\title{
Sensor for Detection of Tobacco Smoke Particulates in Inhalation Exposure Systems*
}

\author{
by C. E. Higgins, T. M. Gayle and J. R. Stokely \\ Analytical Chemistry and Instruments and Controls Division, Oak Ridge National Laboratory, \\ Oak Ridge, Tennessee, U.S.A.
}

\section{INTRODUCTION}

With the increasing use of inhalation techniques in biological studies with tobacco smoke, a need has developed for methods of defining the quantity of smoke to which animals are exposed. Documentation of exposure conditions, for example, requires knowledge of the concentration of smoke offered animals and the duration of the exposure. Evaluation of devices for exposing animals or of new exposure methodologies is made more objective by determination of the quantity of smoke offered with the device or methodology. As the scope of inhalation studies expands to simultaneous exposure of large numbers of animals, suitable means are needed to monitor smoke concentration to prevent accidental overexposure of the animals. Methods for continuous monitoring of smoke aerosols in inhalation systems for these purposes have not been available.

Light scattering techniques offer the potential of continuous, non-destructive monitoring of tobacco smoke in inhalation chambers (1). The technique has been used extensively for the measurement of atmospheric particulates and aerosols $(2,3)$. For aerosols in the size range of tobacco smoke, an approximation of the Mie equation (4) relates the light scattered by an aerosol with particulate concentration of the aerosol:

$$
\mathrm{I}=\mathrm{kr}^{\mathrm{p}} \mathrm{n},
$$

where $\mathrm{I}$ is the scattered light intensity, $\mathrm{n}$ is the particle number concentration, $\mathrm{r}^{\mathrm{p}}$ is the radius of the particles raised to some power $\mathrm{p}$, and $\mathrm{k}$ is a proportionality constant. For a given set of experimental conditions (constant scattering angle, particle radius, wavelength of incident light beam), the intensity of the scattered light is directly proportional to the number of particles per unit volume. An empirical relationship can be established between the scattered light intensity and particle concentration.

In this paper, we describe the development and validation of a simple device for monitoring tobacco smoke particulates by light scattering. The device consists of a commercially available light-emitting diode/phototransistor array which can be interfaced with an inhalation exposure system. The diode element of the array emits light into the smoke aerosol and the light back-scattered

\footnotetext{
Research sponsored jointly by the Council for Tobacco Research - U.S.A. Inc. and the U.S. Energy Research and Development Administration under contract with the Union Carbide Corporation.

Presented, in part, at the 30th Tobacco Chemists' Research Conference, Nashville, Tenn., U.S.A., in October 1976.
}

by the smoke is detected by the phototransistor element. The sensor provides a continuous, nearly instantaneous readout of smoke particulates in the immediate vicinity of the array. Characteristics of the sensor important in the detection and analysis of smoke were investigated and are described in this paper.

\section{EXPERIMENTAL}

\section{Inhalation Exposure System}

The Walton Horizontal Smoking Machine (WHSM), a static (5) inhalation exposure device manufactured by Process and Instruments Corp., Brooklyn, N.Y. (6), was used in this work. This is a "reverse" smoking machine in that air is forced through the cigarette by applying a positive pressure rather than drawing air through the cigarette by reducing the pressure at the butt end. Smoke is puffed into the exposure chamber (384 $\mathrm{ml}$ volume) where it is diluted with air and stands for a preselected time interval up to 45 seconds. Animals positioned around the exposure chamber inhale the smoke during this period. Exposures are terminated by the introduction into the chamber of air (6 liters/minute), which flushes out the smoke. This exposure sequence is repeated at one minute intervals until the cigarette is consumed. A stirrer is provided in the exposure chamber to mix the smoke. A detailed description of the WHSM is available from the manufacturer (6).

\section{Smoke Particulate Sensor and Electronics}

A schematic diagram of the particulate sensor is shown in Figure 1. The combination diode/phototransistor array was a Fairchild FPA $103^{* *}$ (Fairchild Semiconductor, San Jose, Calif.) and consists of a gallium arsenide infrared-emitting diode in combination with a high gain silicon NPN phototransistor. The diode/transistor array is small; its facial dimensions are $0.6 \times 0.5 \mathrm{~cm}$ and its depth, $0.4 \mathrm{~cm}$. For use with the WHSM, the array was incorporated into a probe which could be inserted in a mouse containment tube (Figure 1) so that the array protruded approximately $0.2 \mathrm{~cm}$ into the exposure chamber. Because of the broad wavelength range (400 to $1100 \mathrm{~nm}$ ) over which the phototransistor element is sensitive, it was necessary to cover the exposure chamber with black plastic to reduce the impingement of room light on the element.

$*$ An Optron OPB-710 (Optron Inc., Carrollton, Tex.) array has also been used in recent studies. 
Figure 1. Schematic diagram of particulate sensor and associated electronics.

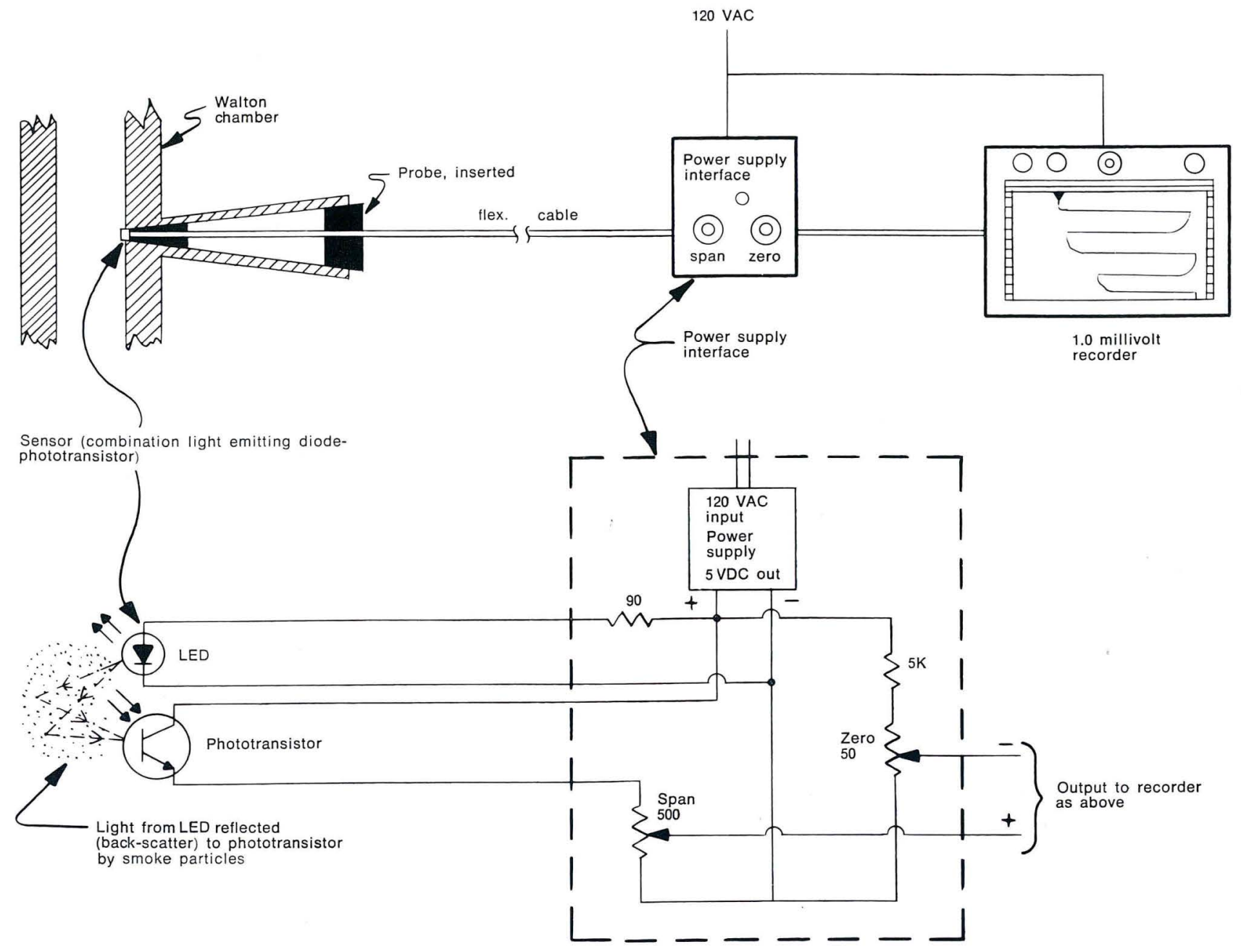

Electronics designed for use with the particulate sensor are shown in Figure 1. The span potentiometer provides adjustment of the sensitivity of the phototransistor element of the array. Sensitivity is adjustable to provide full scale readout $(1 \mathrm{mV})$ for smoke particulate concentrations normally encountered in inhalation work. The zero control is designed to zero the response of the sensor with no smoke present at the sensor array.

\section{Sampling and Analysis of Smoke}

Smoke particulates were sampled from the WHSM chamber by a pulse sampling technique in which a known volume of smoke was withdrawn from the inhalation system over a short time interval. Normally, a $38 \mathrm{ml}$ sample of smoke was taken over a 2-second interval using a vacuum smoking machine described previously (7). Smoke particulates were collected on a small Cambridge filter pad (13 $\mathrm{mm}$ diameter) enclosed in a Swinnex millipore filter holder (Millipore Corp., Bedford, Mass.). Total particulate matter (TPM) was determined by weighing the TPM collected on the pad. Nicotine was determined by gas chromatographic analysis (8) of ethanol extracts of TPM collected on the filter pad. Nicotine and TPM results were expressed as the weight concentration in the sampled smoke. These results were obtained by dividing the weight of TPM or nicotine found on the filter pad by the total volume of smoke pulled through the pad.

\section{Cigarettes}

Cigarettes used in this work were either Kentucky reference $1 \mathrm{R} 1$ or $1 \mathrm{~A} 1$ cigarettes (University of Kentucky, Lexington, Kentucky) or cigarettes manufactured for the National Cancer Institute (NCI), Bethesda, Maryland. Cigarettes were conditioned by storage for at least 48 hours at $60 \pm 2 \%$ relative humidity and $297 \pm 1 \mathrm{~K}$ $\left(24 \pm 1{ }^{\circ} \mathrm{C}\right)$. All cigarettes were selected on the basis of weight ( $\pm 20 \mathrm{mg}$ of average weight) and resistanceto-draw (RTD) ( $\pm 5 \mathrm{~mm} \mathrm{H} \mathrm{H}_{2} \mathrm{O}$ of average $\mathrm{RTD}$ ).

\section{RESULTS AND DISCUSSION}

Figure 2 illustrates the response of the monitor to successive puffs of smoke being taken into the exposure chamber. The WHSM operating parameters were set to introduce one $35 \mathrm{~cm}^{3} / 2 \mathrm{~s}$ puff from a single cigarette into the chamber once per minute. Each puff of smoke was allowed to stand in the chamber for $30 \mathrm{~s}$ before exhausting the chamber with fresh air. The sixth puff was allowed to remain in the chamber, and grab samples were taken 
Figure 2. Sensor response to smoke in the Walton horizontal exposure system. Five puffs allowed to remain in chamber for $30 \mathrm{~s}$, purge air off after introduction of sixth puff, grab sampling chamber content at points $A$ and $\mathrm{B}$.

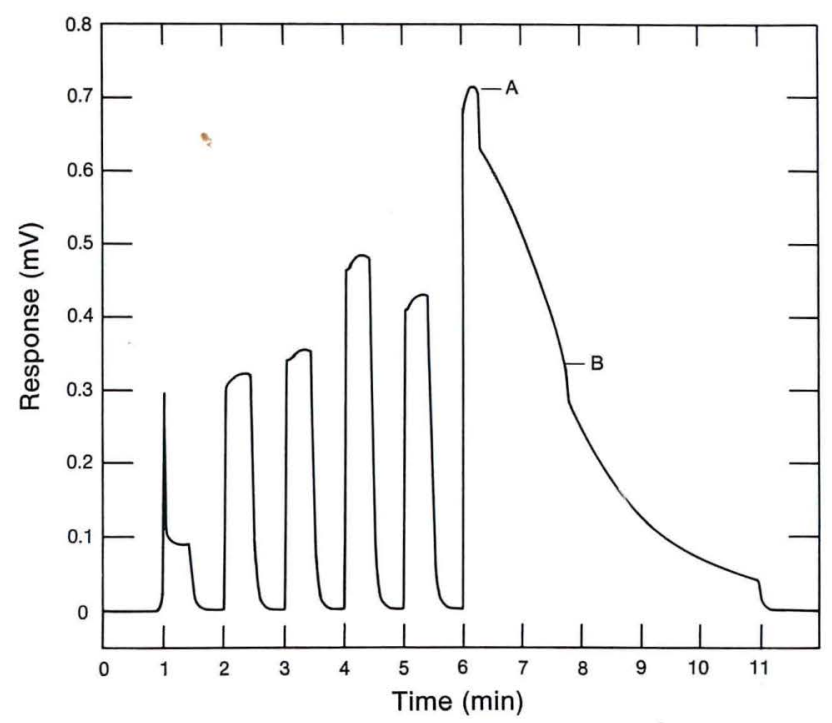

at points $A$ and B (Figure 2) to study the influence of particle size growth on monitor response.

The lighting puff is characterized by a sharp excursion of the recorder output as the phototransistor senses the glowing electric lighter, followed by a rapid decay as the lighter moves away from the chamber and, finally, a generally stabilized response to scattered light from the smoke particulates. The response then decays to background level as the particulates are swept from the chamber with fresh air. Subsequent puffs result in a rapid increase in response as the smoke enters the chamber, a slow increase during the stand period, and a. decay to background as the smoke is swept from the chamber. The slow increase in response during the stand period is presumably related to particle size growth.

Response time is essentially instantaneous with the primary limitation being the response time of the recorder. As is apparent from Figure 2, there is no difficulty with zero shift between puffs. Extended experimentation with the device has demonstrated a constant return to baseline during the smoking of at least twelve consecutive cigarettes and only very minor excursions until the sensor window becomes coated with smoke condensate. A fouled sensor can be returned to routine use following a methanol rinse of the window.

The functional relationship between sensor response and smoke concentration was established by correlation of independently determined TPM concentration in the WHSM with the signal from the sensor. Results of this study illustrated in Figure 3 clearly demonstrate a linear relation between sensor readout and TPM concentration. Each data point represents the sensor readout and TPM concentration of the smoke in the exposure chamber averaged over all puffs from each cigarette (1R1). Scatter in the data is due primarily to errors in weighing the small quantities of TPM $(2-12 \mathrm{mg})$ col-
Figure 3. Voltage response of particulate sensor to smoke of varying total particulate matter (TPM) concentration. $\bigcirc$ initial results two months later

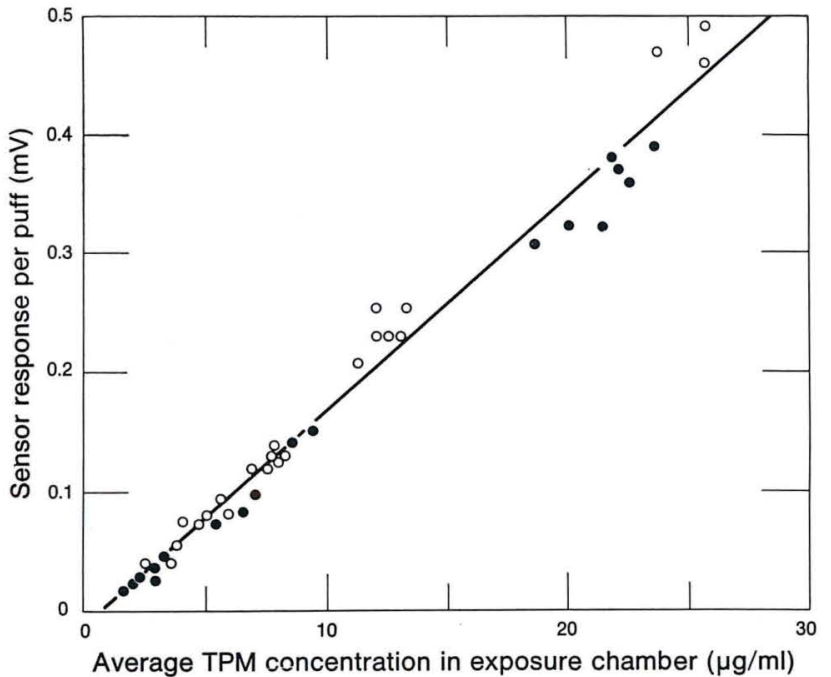

lected on filter pads. In spite of this variation, a correlation coefficient of 0.99 is found between sensor response and TPM. Data for this study were taken at two different times to assess the long term reproducibility of the sensor. Reproducibility appears good over at least a two-month period.

Linearity in the response of the particulate sensor was confirmed by analysis of nicotine in smoke sampled from the WHSM. Sensitivity for nicotine analysis was sufficient to permit nicotine determinations on smoke sampled from individual puffs of the cigarette. Figure 4 shows a correlation plot of data collected in this study. Again, a linear relationship between smoke concentration (as measured by nicotine) and sensor readout is apparent; the correlation coefficient for this linearly related data is 0.97 .

The fact that the output from the particulate sensor is linearly related to smoke aerosol concentration is predicted by the approximation of the Mie equation cited previously. Linearity in the response makes interpretation of data straightforward, allows easy visualization of relative smoke concentration levels, and simplifies calibration of the sensor for quantitative documentation of exposure conditions.

Aging of smoke in inhalation systems is a potential complication in utilization of the particulate sensor. Smoke aerosols agglomerate on aging to form particles of larger size (9) which could result in significant changes in the response of the particulate sensor. The effect of aerosol agglomeration on the response of the sensor is observable on the response profile for the WHSM shown on Figure 2. The small increase in signal level on each of the response peaks is due primarily to agglomeration effects. During the 30-second exposure period in which smoke stands in the WHSM exposure chamber, agglomeration causes the sensor response to increase $4-8 \%$ from the initial response.

The possibility of additional changes in sensor response at longer exposure intervals was investigated by allow- 
Figure 4. Correlation of sensor response with nicotine concentration for single puffs on 1R1 cigarettes.

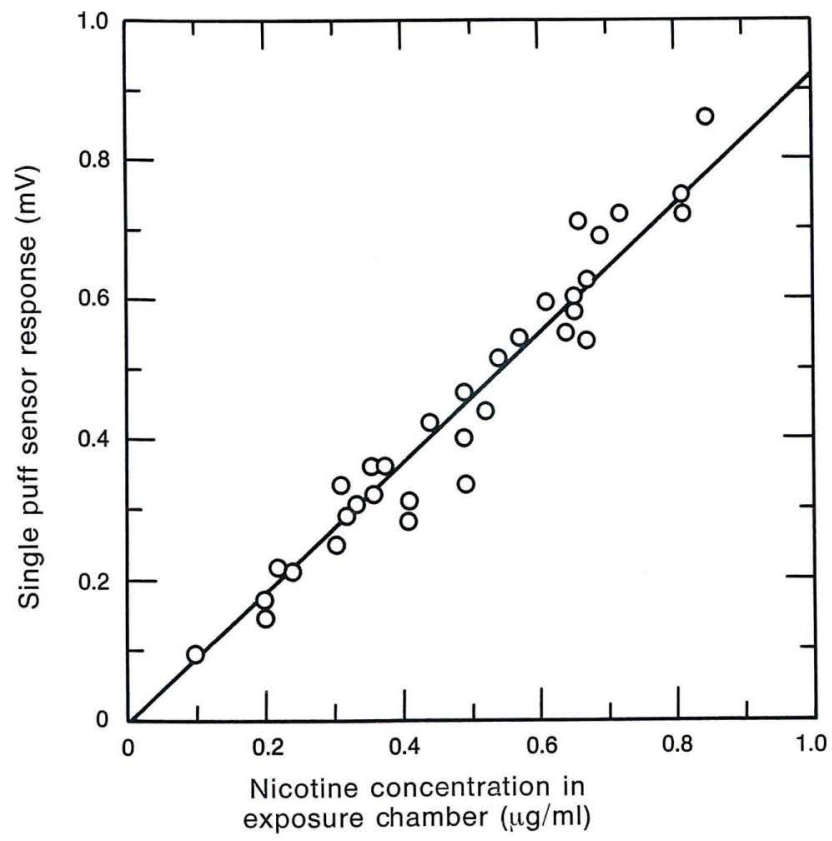

ing puffs of smoke to age for extended time periods in the WHSM chamber. Puff 6 of Figure 2 shows a typical response profile obtained in the study. During the extended exposure smoke particulates are lost from the exposure chamber by settling and impaction on the chamber walls and the stirrer. Therefore, it was necessary to withdraw samples from the exposure chamber (at time points $\mathrm{A}$ and $\mathrm{B}$ ) in order to determine the actual concentration of smoke aerosol suspended in the chamber atmosphere. Withdrawn samples were analyzed for nicotine. Samples were withdrawn approximately 15 seconds after the puff was taken and again $2-3$ minutes later. A comparison was then made between the ratio of smoke concentrations measured at sampling times $\mathrm{A}$ and $\mathrm{B}$ and the ratio of responses of the particulate sensor at the same times. Results of this comparison are shown in Table 1. Fresh and aged smoke on this table refer to smoke sampled early (A) and late

Table 1. Comparison of light sensor response ratio with nicotine ratio for fresh and aged smoke.

\begin{tabular}{c|c|c|c|c|c}
\hline $\begin{array}{c}\text { 1R1 } \\
\text { puff } \\
\text { No. }\end{array}$ & $\begin{array}{c}\text { Type } \\
\text { of } \\
\text { smoke }\end{array}$ & $\begin{array}{c}\text { Response } \\
(\mathrm{mV})\end{array}$ & $\begin{array}{c}\text { Nicotine } \\
\text { concen- } \\
\text { tration } \\
(\mu \mathrm{g} / \mathrm{ml})\end{array}$ & \multicolumn{2}{|c}{$\begin{array}{c}\text { Ratios, } \\
\text { fresh/aged }\end{array}$} \\
\cline { 5 - 6 } 11 & Response & Nicotine \\
\hline 7 & fresh & 0.72 & 0.72 & 2.5 & 2.3 \\
& aged & 0.29 & 0.31 & & \\
\hline 7 & fresh & 0.55 & 0.64 & 2.6 & 2.7 \\
& aged & 0.21 & 0.24 & & \\
\hline 7 & fresh & 0.61 & 0.64 & 2.0 & 1.9 \\
& aged & 0.30 & 0.33 & & \\
\hline 6 & fresh & 0.71 & 0.66 & 2.1 & 2.1 \\
& aged & 0.34 & 0.31 & & \\
\hline
\end{tabular}

Figure 5. Total sensor response for cigarettes of different types and total particulate matter deliveries.

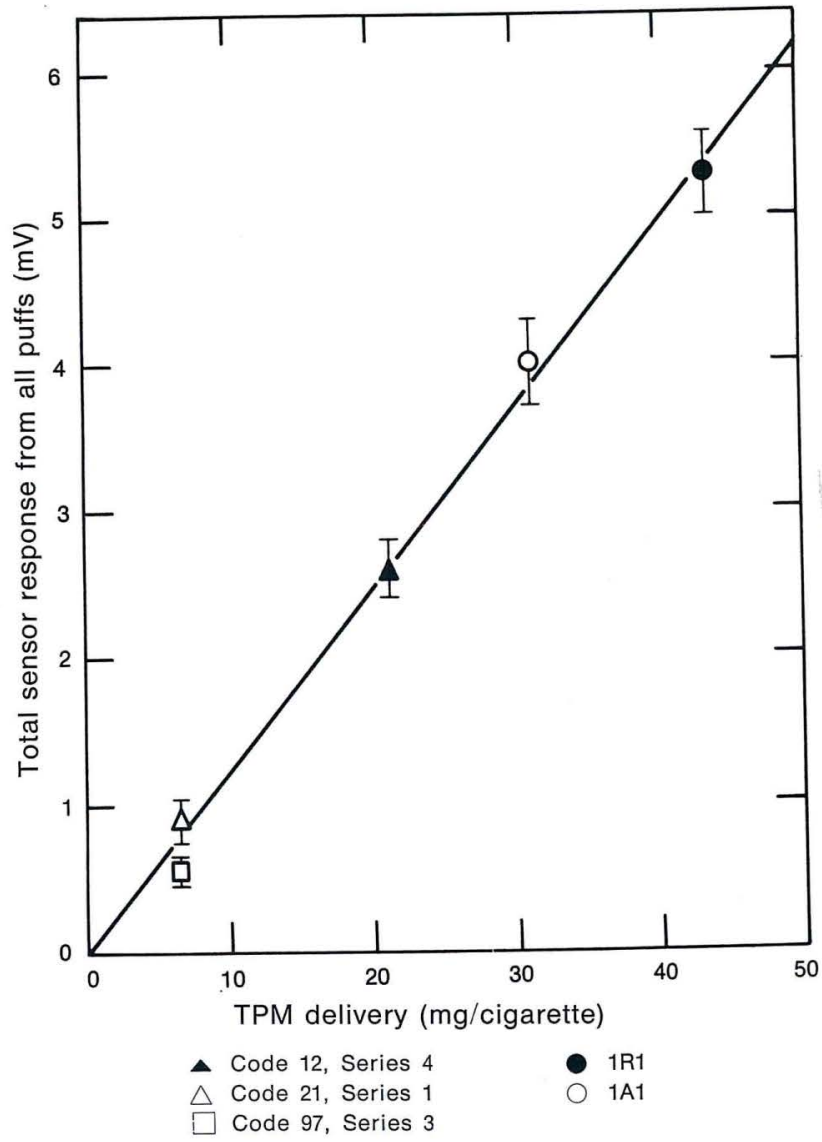

(B) in the extended exposure period. The ratio of sensor responses and nicotine concentrations at the two sampling times were calculated for randomly selected puffs on the cigarettes.

Agreement between the two ratios is indicative of little agglomeration effect on sensor response. As seen in Table 1 for different puffs on 1R1 cigarettes, close agreement is indeed apparent; the ratios differ by only a few percent. Therefore, it is concluded that aging has very little effect on sensor response for smoke aged for extended periods. Immediately after smoke is generated, however, agglomeration does produce observable but small changes in sensor response and this fact must be taken into account in interpreting results obtained with the particulate sensor.

Response of the particulate sensor to smokes from different types of cigarettes was examined to investigate the possible effects of smoke composition on response. Cigarettes of five different types were smoked on the WHSM, and sensor response profiles were obtained for smoke in the exposure chamber. Responses from all puffs on each cigarette were measured at the maxima of the response profiles and were summed to form a total response for the entire cigarette. Figure 5 shows a plot of the measured total response as a function of the TPM delivery of the cigarettes determined with the Phipps and Bird analytical smoking machine (Phipps and Bird, Inc., Richmond, Virginia). Except for one cigarette (NCI Code 97), total sensor response is linearly related to 
TPM delivery of the cigarettes. Therefore, these results indicate that the specific response of the sensor (response per mg TPM) is independent of cigarette type; the sensor responds only to the concentration of smoke particulates, and the composition of the smoke is inconsequential. The specific response of the NCI Code 97 cigarette is slightly low in comparison with the specific response of the other cigarettes. This cigarette is made from substitute tobacco, and the particle size of substitute tobacco smoke has a smaller mean value than the particle size of smoke from cigarettes made from natural tobacco (10). It is probably this difference in particle size that accounts for the lower specific response of the smoke from cigarettes made from a tobacco substitute.

\section{SUMMARY}

A commercially available light emitting diode/phototransistor array was investigated for detection and analysis of tobacco smoke in the Walton Horizontal Smoking Machine (WHSM) animal inhalation exposure system. The diode element of the device emits light into the smoke aerosol, and light back-scattered by the smoke particles is detected by the phototransistor element. The sensor provides a continuous, nearly instantaneous graphical visualization of smoke particulates in the immediate vicinity of the array. Experimental studies showed that sensor readout is linearly related to smoke particulate concentration of the smoke and is independent of the composition of the smoke. Smoke particle agglomeration associated with aging of smoke causes observable but minor changes in sensor response.

\section{ZUSAMMENFASSUNG}

Es wurde geprüf, ob sich eine im Handel erhältliche lichtausstrahlende Diode/Phototransistor-Apparatur zum Einsatz bei der Bestimmung und der Analyse von Tabakrauch in der Walton-Berauchungsanlage für Versuchstiere (WHSM/Walton Horizontal Smoking Machine) eignet. Das Diodenelement des Gerätes sendet Licht in das Rauchaerosol, und das von den Rauchpartikeln zurückgestreute Licht wird von dem Phototransistorelement erfaßt. Durch das Sensorelement werden die in der Nähe der Versuchsanordnung befindlichen Rauchpartikel kontinuierlich fast unmittelbar nach ihrer Entstehung graphisch sichtbar gemacht. Im Experiment zeigte sich, daß die Anzeigewerte des Sensorelementes in linearer Beziehung zur Konzentration der Rauchpartikel stehen und unabhängig von der Zusammensetzung des Rauches sind. Durch Altern des Rauches bedingte Agglomeration der Rauchpartikel hatte meßbare, aber geringfügige Veränderungen der Sensorreaktion zur Folge.

\section{RÉSUMÉ}

Un dispositif diode/phototransistor vendu dans le commerce a été examiné en vue de son utilisation pour la détection et l'analyse de la fumée de tabac dans la machine à fumer horizontale Walton (WHSM) servant à exposer des animaux à l'inhalation. L'élément diode du dispositif projette de la lumière dans l'aérosol de fumée, et la lumière renvoyée par les particules de fumée est détectée par l'élément phototransistor. Le sensor produit une image graphique continue et presque instantanée des particules de fumée à proximité immédiate du dispositif. Des études expérimentales ont montré que l'indication fournie par le sensor est en corrélation linéaire avec la concentration des particules de fumée et qu'elle est indépendante de la composition de la fumée. L'agglomération des particules de fumée associée au vieillissement de la fumée provoque des changements perceptibles mais minimes dans la réaction du sensor.

\section{REFERENCES}

1. Penkala, S. J., and G. de Oliveira: The simultaneous analysis of carbon monoxide and suspended particulate matter produced by cigarette smoking; Environmental Research 9 (1975) 99.

2. Channell, J. K., and R. J. Hanna: Experience with light scattering particle counters; Arch. Environ. Health 6 (1963) 386.

3. Nader, J. S., G. C. Ortman and M. T. Massey: Light-scatter instrumentation for measurement of atmospheric particulates; J. Am. Ind. Hyg. Assoc. 22 (1961) 42.

4. Green, H. L., and W. R. Lane: Particulate clouds; D. Van Nostrand Company, Inc., Princeton, N.J., 1964, p. 119.

5. Guerin, M. R., W. L. Maddox and J. R. Stokely: Tobacco smoke inhalation exposure: concepts and devices; Proceedings of the Tobacco Smoke Inhalation Workshop, Bethesda, Md., June 19-21, 1974, U.S. Department of Health, Education, and Welfare Publication No. (NIH) 75-906.

6. Walton Smoke Exposure Machine: Instruction manual; Process and Instruments Corp., Brooklyn, N.Y.

7. Horton, A. D., and M. R. Guerin: Determination of acetaldehyde and acrolein in the gas phase of cigarette smoke using cryothermal gas chromatography; Tob. Sci. 18 (1974) 19.

8. Lyerly, L. A., and G. H. Greene: Determination of nicotine in low-nicotine tobacco; Beitr. Tabakforsch. 8 (1976) 359.

9. Keith, C. H., and J. C. Derrick: Measurement of the particle size distribution and concentration of cigarette smoke by the "conifuge"; J. Colloid Sci. 15 (1960) 340.

10. Holmberg, R. W., and L. B. Yeatts: Particle size characteristics of tobacco smoke; Anal. Chem. Div. Annu. Rep. Nov. 30, 1976, ORNL-5244, p. 72 / Available from National Technical Information Service, Springfield, Va., 22161.

Authors' address:

Analytical Chemistry Division, Oak Ridge National Laboratory,

P.O. Box $X$,

Oak Ridge, Tennessee, 37830, U.S.A. 